\title{
Estimating dementia cases amongst migrants living in Europe
}

\author{
M. Canevelli, ${ }^{a, b}$ (ID, E. Lacorte ${ }^{b}$, I. Cova ${ }^{c}$, V. Zaccaria ${ }^{a}$, M. Valletta ${ }^{a}$, R. Raganato ${ }^{a}$, G. Bruno $^{a}$, \\ A. M. Bargagli ${ }^{d}$, S. Pomatic ${ }^{\mathrm{C}}$ L. Pantoni ${ }^{\mathrm{e}}$ (D) and N. Vanacore ${ }^{\mathrm{b}}$
}

\begin{abstract}
a Department of Human Neuroscience, 'Sapienza' University, Rome; ${ }^{\mathrm{b}}$ National Center for Disease Prevention and Health Promotion, National Institute of Health, Rome; 'Center for Research and Treatment on Cognitive Dysfunctions, 'Luigi Sacco' University Hospital, Milan; ${ }^{\mathrm{d}}$ Department of Epidemiology, Regional Health Service, Rome; and ${ }^{\mathrm{e}}$ Department of Biomedical and Clinical Sciences 'Luigi Sacco', University of Milan, Milan, Italy
\end{abstract}

\section{Keywords:}

cognitive disturbances, cross-cultural assessment, dementia, epidemiology, migration, public health

Received 12 November 2018 Accepted 4 April 2019

European Journal of Neurology 2019, 0: 1-9

doi:10.1111/ene.13964
Background and purpose: The phenomenon of dementia amongst migrants and ethnic minorities represents an emerging concern for European healthcare systems, posing additional challenges in terms of clinical approach, access to care and resource utilization. The aim of the present study was to estimate the cases of dementia amongst immigrant older subjects living in Europe and in each European country.

Methods: The estimated cases of dementia amongst older (i.e. $65+$ ) migrants living in the European Union (EU-28) and European Free Trade Association member states were calculated by multiplying the number of migrants (obtained through the data provided by Eurostat) with the age- and sex-specific prevalence rates (derived by a recent meta-analysis).

Results: Overall, 6507360 older migrants lived in Europe in 2017. In addition, 1204671 migrants were registered in Germany in 2010. Nearly 475000 dementia cases (329 028 women, $147410 \mathrm{men}$ ) were estimated in this population by applying age- and sex-specific prevalence rates. When considering each European country, the number of estimated cases ranged from 108 (Iceland) to 119161 (France). In parallel, the proportion of dementia cases occurring in migrants ranged from $0.9 \%$ (Czech Republic) to $51.2 \%$ (Liechtenstein).

Conclusions: The issue of dementia in migrants and ethnic minorities is emerging but already relevant for European healthcare systems. The magnitude of this phenomenon and its complexities reinforce the need for coordinated initiatives both at a national and continental level. These epidemiological data should ideally be integrated with those coming from 'real world' services in order to better calibrate these actions.

\section{Introduction}

The term 'migrant' refers to any person who is moving or has moved across an international border or within a State away from his/her habitual place of residence, regardless of the person's legal status, the causes and voluntary/involuntary nature of the movement, and the length of stay [1]. To date, international migrants (i.e. subjects born outside their current

Correspondence: M. Canevelli, Department of Human

Neuroscience, 'Sapienza' University of Rome, Viale dell'Università 30, 00185 Rome, Italy (tel./fax: + 39 (0)6 49914604;

e-mail: marco.canevelli@gmail.com). country of residence) account for $11.5 \%$ of the overall European population. Amongst these people, about 20 million individuals are from non-EU developing countries (source: Eurostat 2017, http://ec.europa.eu/ eurostat). This immigrant population is steadily growing older, thus increasingly facing the burden of age-related pathological conditions. In particular, the phenomenon of dementia and cognitive disturbances in this heterogeneous group of subjects represents an emerging concern for European healthcare systems [2]. In fact, the occurrence of dementing illnesses in older migrants poses additional challenges for a number of reasons [2-5]. These individuals may have a limited 
knowledge of the host country's language and a low educational level [6], thus making cognitive testing less reliable and accurate [7]. The diagnostic approach is also hampered by the poor availability and implementation of instruments that are appropriate for crosscultural assessment of cognitive skills and deficits [810]. Cultural, spiritual and economic barriers as well as healthcare inadequacies may postpone medical help-seeking for cognitive disturbances and result in a reduced access to treatments, resources and support [3,11-14]. All these aspects might assume a greater relevance amongst people migrating from disadvantaged countries and ethnic minority groups, due to low employment levels, limited social support and access to education, and lower socioeconomic status.

Based on these considerations, there is a growing consensus recognizing the need to promote targeted strategies and policies to tackle this novel public health issue [11]. A first, pivotal step in this direction should inevitably be represented by the estimation of its magnitude and relevance in order to better design and calibrate future actions and initiatives [15].

The aim of the present study was to estimate the cases of dementia amongst immigrant older subjects living in Europe and in each European country. More specifically, the focus was on the member states of the European Union (EU-28) and the European Free Trade Association (EFTA).

\section{Methods}

\section{Older migrants in Europe}

The number of migrants living in Europe, aged 65 years or older, was obtained through the data provided by the Statistical Office of the European Union, Eurostat (http://ec.europa.eu/eurostat/web/populationdemography-migration-projections/population-data/da tabase). Subjects living in a given European country but born abroad were operationally identified as 'migrants' for the present analysis, regardless of the length of stay and the causes for the migration [1]. Age- and sex-specific data were available for the 28 countries of the European Union plus the four countries of the EFTA (i.e. Iceland, Liechtenstein, Norway and Switzerland). All data were updated to 2017 except for Germany (last update in 2010). No information was available for Germany concerning the 80 84 year and 85-90 year age classes. Data were also abstracted concerning the country of birth of immigrant individuals, considering both geographical (i.e. continent and sub-continental region) and socioeconomic aspects (i.e. income, life expectancy, literacy, education) [16]. However, detailed information on the geographical area of the countries of origin was available only for the $38.3 \%$ of the total older immigrant population living in Europe.

\section{Dementia prevalence rates}

The age- and sex-specific prevalence estimates of dementia were derived by a recent meta-analysis [17] of population-based European studies adopting the Diagnostic and Statistical Manual of Mental Disorders - IV edition criteria [18] and meeting the highest standards of methodological quality according to the Alzheimer Disease International standardized scoring system [19]. Nine studies, accounting for 18263 overall participants and 2137 dementia cases, were included.

\section{Estimated dementia cases amongst migrants}

The estimated cases of dementia amongst older migrants living in Europe, and in each of the 32 countries considered, were calculated by multiplying the number of migrants with the age- and sex-specific prevalence rates. For each of the considered countries,

Table 1 Estimated dementia cases amongst migrants living in Europe (EU-28 and EFTA) in 2017

\begin{tabular}{|c|c|c|c|c|c|c|}
\hline \multirow[b]{2}{*}{ Age } & \multicolumn{3}{|l|}{ Men } & \multicolumn{3}{|l|}{ Women } \\
\hline & Prevalence $(\%)^{\mathrm{a}}$ & Migrants $(n)^{\mathrm{b}}$ & Estimated cases $(n)$ & Prevalence $(\%)^{\mathrm{a}}$ & Migrants $(n)^{\mathrm{b}}$ & Estimated cases $(n)$ \\
\hline $65-69$ & 0.9 & 1162015 & 10458 & 1.1 & 1319729 & 14517 \\
\hline $70-74$ & 2.1 & 897734 & 18852 & 2.2 & 1008898 & 22196 \\
\hline $75-79$ & 4.6 & 658585 & 30295 & 5.6 & 809705 & 45343 \\
\hline $80-84^{\mathrm{c}}$ & 9.0 & 394775 & 35530 & 13.3 & 569123 & 75693 \\
\hline $85-89^{c}$ & 13.9 & 183921 & 25565 & 26.4 & 321532 & 84884 \\
\hline$\geq 90$ & 31.2 & 85608 & 26710 & 38.9 & 222093 & 86394 \\
\hline Total & & 3382638 & 147410 & & 4251080 & 329028 \\
\hline
\end{tabular}

${ }^{\mathrm{a}}$ Age- and sex-specific prevalence rates were taken from reference [17]; ${ }^{\mathrm{b}}$ Source: Eurostat (http://ec.europa.eu/eurostat/web/population-demogra phy-migration-projections/population-data/database); data are updated to 2017 except for Germany (2010); ${ }^{\mathrm{N}}$ No data were available for Germany concerning these specific age classes. 


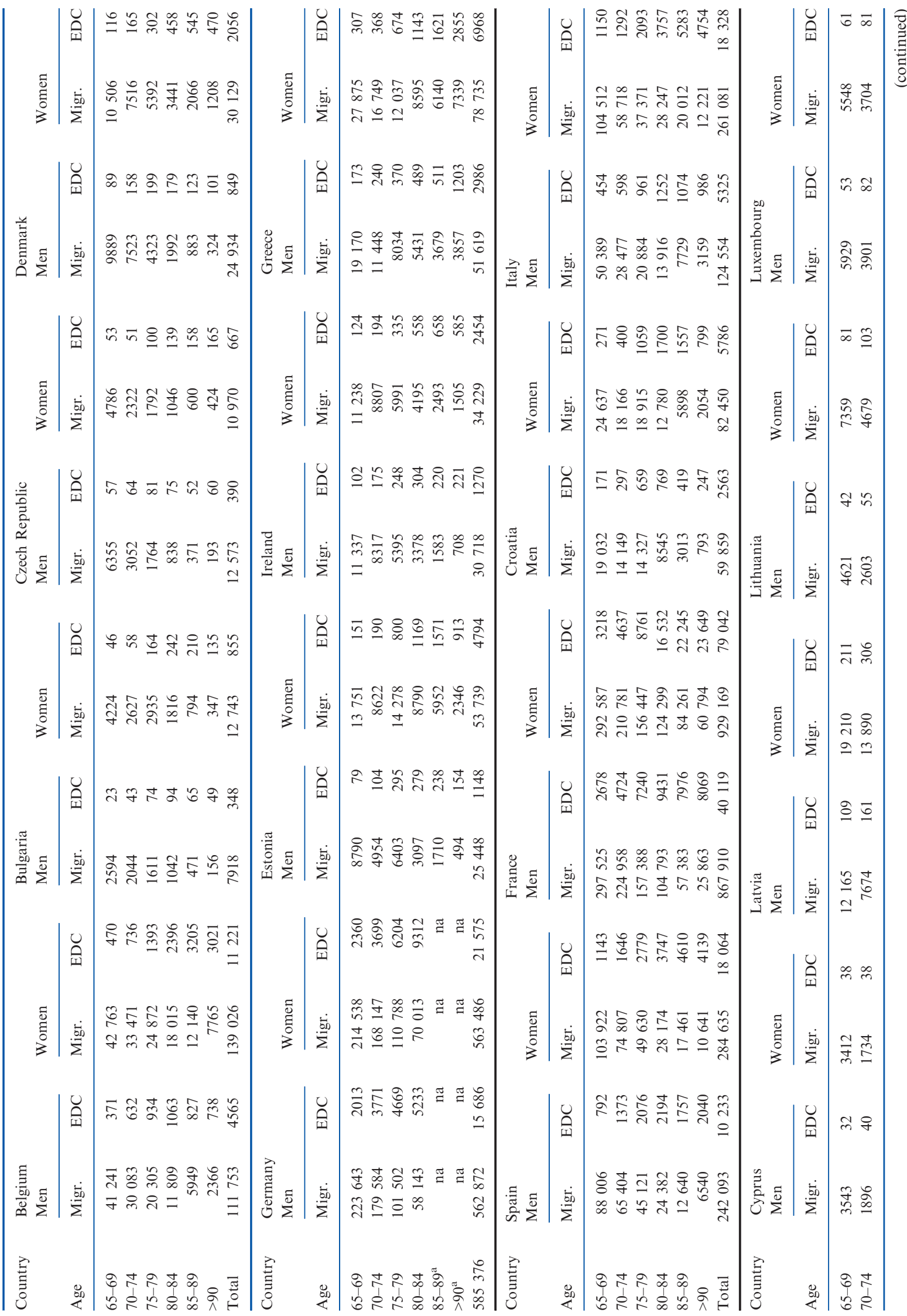




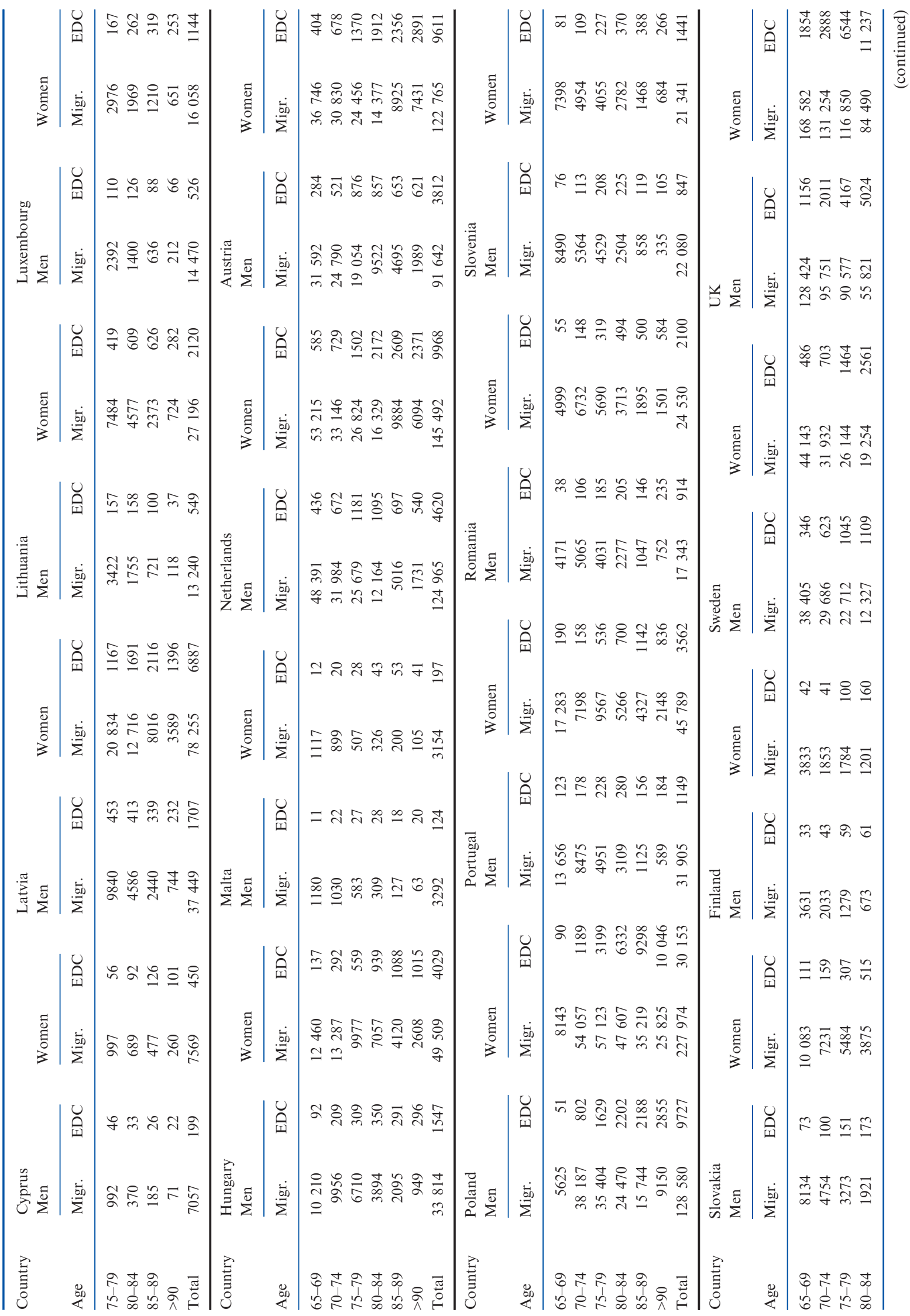




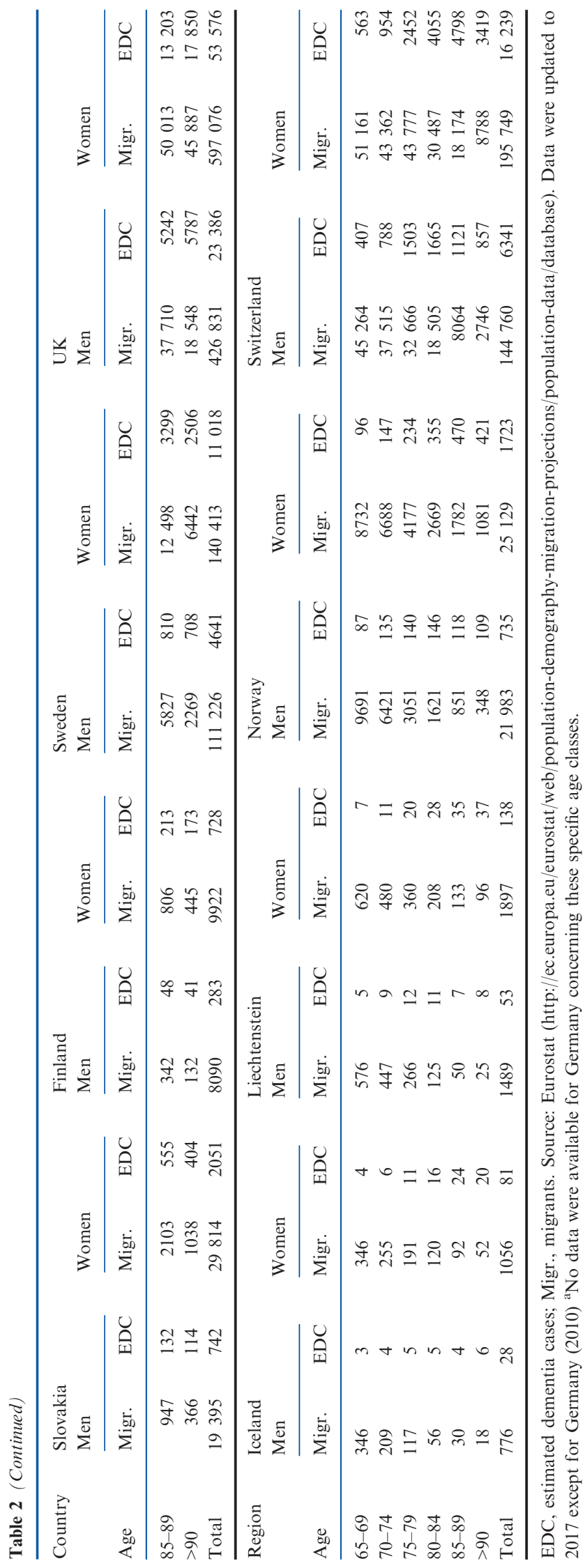


the proportion of dementia cases occurring in migrants (calculated as the ratio between the estimated cases in migrants and in the overall population) was also estimated.

\section{Results}

Overall, 6507360 older migrants (women 55.7\%) lived in Europe in 2017 (Table 1), with national estimates ranging widely from 1832 in Iceland to 1797079 in France (Table 2). In addition, 1204671 migrants were registered in Germany on 2010. The majority of immigrant subjects were born in another EU-28 or EFTA country. However, more than 2 million were first-generation immigrants from less and medium developed non-European countries. Based on available data, a relevant number of individuals came from outside the extended EU, Canada, USA, Australia and New Zealand, thus possibly composing ethnic minority groups once they moved to Europe [2].

Nearly 476500 dementia cases (329028 women, 147410 men) were estimated in the over 65-year-old European immigrant population by applying age- and sex-specific prevalence rates (Table 1). When considering each European country, the number of estimated cases ranged from 108 (Iceland) to 119161 (France) with a marked inter-national variability (median 5144; interquartile range 2134-15 691) (Table 2). The proportion of dementia cases occurring in migrants (i.e. the ratio between the estimated cases in migrants and

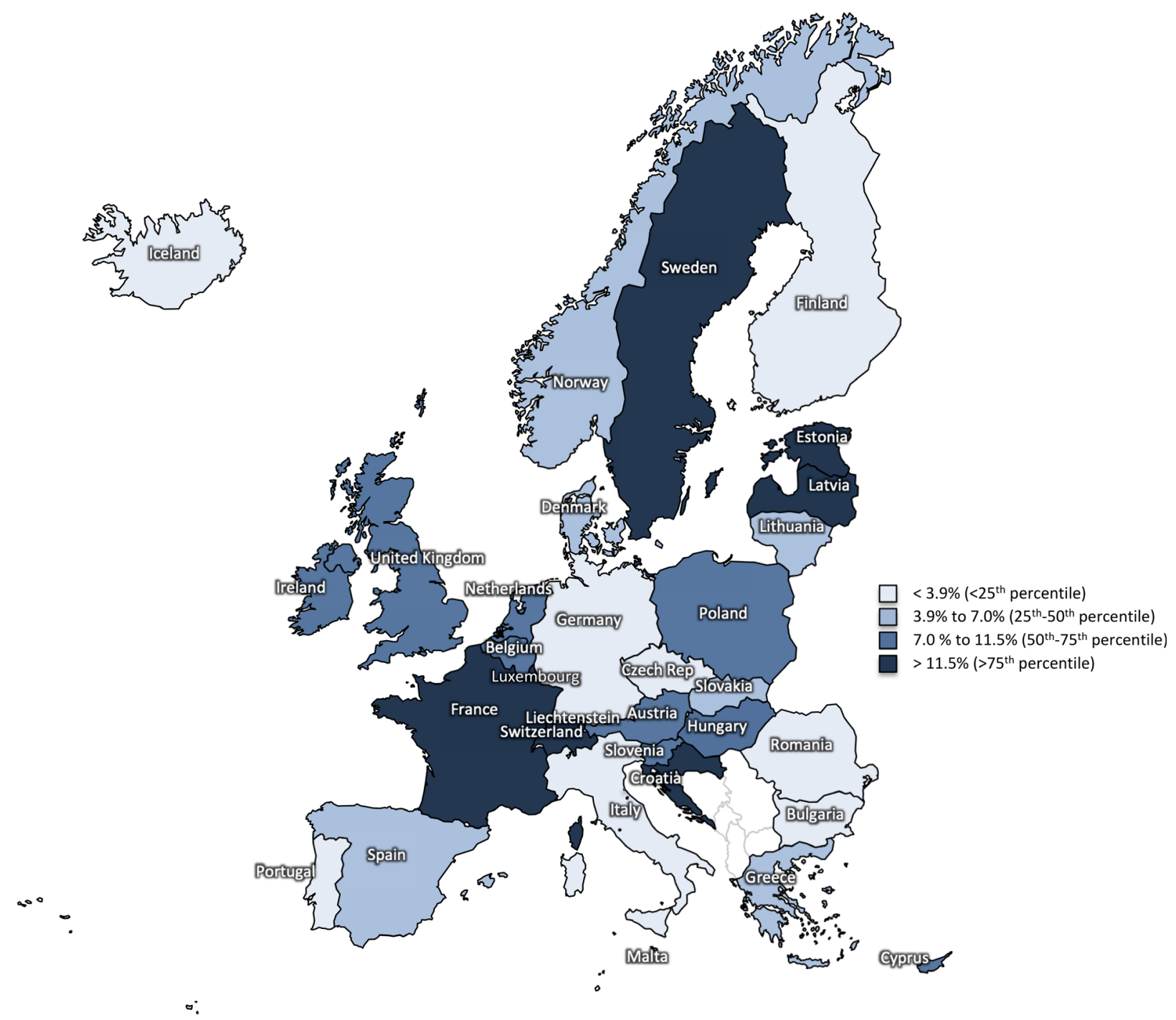

Figure 1 Proportion of dementia cases occurring in migrants in the 32 countries considered. [Colour figure can be viewed at wileyonlinelibrary.com] 
in the overall population) ranged from $0.9 \%$ (Czech Republic) to $51.2 \%$ (Liechtenstein) (median 7.0\%; interquartile range $3.9 \%-11.5 \%$ ) (Fig. 1 and Table 3).

\section{Discussion}

To our knowledge, the present study constitutes the first attempt to describe and characterize the issue of dementia occurring in the immigrant population living in Europe. Based on our findings, a non-negligible number of migrants might seek or are already seeking help for cognitive disturbances, thus potentially referring to clinical and social services in their novel European country of residence, with relevant healthcare and societal implications. In particular, according to our estimates, nearly $6.5 \%$ of overall cases of dementia in Europe is expected to involve foreign-born populations (476 438 out of 7279151 total cases). It is

Table 3 Proportion of dementia cases occurring in migrants in the 32 countries considered

\begin{tabular}{|c|c|c|c|}
\hline Country & $\begin{array}{l}\text { Estimated } \\
\text { cases in } \\
\text { migrants }(n)\end{array}$ & $\begin{array}{l}\text { Estimated cases } \\
\text { in the overall } \\
\text { population }(n)\end{array}$ & $\begin{array}{l}\text { Estimated } \\
\text { proportion of } \\
\text { cases in migrants } \\
(\%)\end{array}$ \\
\hline Liechtenstein & 190 & 371 & 51.2 \\
\hline Estonia & 5942 & 18231 & 32.6 \\
\hline Latvia & 8594 & 26894 & 32.0 \\
\hline Luxembourg & 1670 & 5874 & 28.4 \\
\hline Switzerland & 22580 & 109437 & 20.6 \\
\hline Croatia & 8348 & 51950 & 16.1 \\
\hline France & 119161 & 1005787 & 11.8 \\
\hline Sweden & 15659 & 134747 & 11.6 \\
\hline Austria & 13423 & 116955 & 11.5 \\
\hline Belgium & 15786 & 156704 & 10.1 \\
\hline Poland & 39880 & 412267 & 9.7 \\
\hline UK & 76962 & 822180 & 9.4 \\
\hline Ireland & 3724 & 39848 & 9.3 \\
\hline Cyprus & 649 & 7600 & 8.5 \\
\hline Slovenia & 2288 & 26926 & 8.5 \\
\hline Netherlands & 14589 & 200953 & 7.3 \\
\hline Lithuania & 2668 & 39511 & 6.8 \\
\hline Malta & 322 & 5003 & 6.4 \\
\hline Slovakia & 2794 & 47212 & 5.9 \\
\hline Greece & 9954 & 173882 & 5.7 \\
\hline Hungary & 5576 & 114211 & 4.9 \\
\hline Denmark & 2905 & 67940 & 4.3 \\
\hline Norway & 2458 & 59380 & 4.1 \\
\hline Spain & 28297 & 697404 & 4.1 \\
\hline Iceland & 108 & 3126 & 3.5 \\
\hline Portugal & 4711 & 155879 & 3.0 \\
\hline Germany & 37261 & 1237249 & 3.0 \\
\hline Italy & 23653 & 1045718 & 2.3 \\
\hline Bulgaria & 1203 & 85346 & 1.4 \\
\hline Romania & 3014 & 219006 & 1.4 \\
\hline Finland & 1012 & 76305 & 1.3 \\
\hline $\begin{array}{l}\text { Czech } \\
\text { Republic }\end{array}$ & 1056 & 115255 & 0.9 \\
\hline
\end{tabular}

noteworthy that, although this phenomenon is mostly involving subjects coming from other European states, a sizeable proportion of cases is probably affecting individuals migrating from low and middle income countries, thus probably with lower socioeconomic status, a different cultural background and reduced access to care. These numbers are projected to increase further in the next years in the light of the ongoing sociodemographic changes and the growing extent of migratory flows to Europe. Moreover, it is likely that the future implementation of nosological classifications incorporating also potential pre-dementia conditions (e.g. mild cognitive impairment) will further increase the dimension of the problem.

Of course, these data should be combined with those coming from the 'real world' to achieve a better comprehension of this emerging phenomenon. To date, most of the available evidence on the topic has emerged by national registry based studies that have shown that, in some European countries (e.g. Norway, Denmark and Sweden), immigrants have a lower likelihood of receiving a diagnosis of dementia and antidementia treatment compared to their native counterparts [12,20,21]. Conversely, only few studies have attempted to characterize and explore the magnitude of this issue at the services level. A recent survey conducted in 15 European countries confirmed that memory clinics still have a limited experience with nonEuropean migrants and ethnic minority groups. In particular, $80 \%$ of the centres reported to have $<5 \%$ of non-western older subjects amongst the overall referred patients. Moreover, the clinical approach to these patients was considered to be challenging by nearly two-thirds of centres, mostly due to communication problems and lack of adequate assessment tools [2]. There is also sparse evidence that the number of subjects migrated from disadvantaged contexts attending dementia services is increasing. For example, in Belgium, the proportion of first-generation immigrants from non-EU countries referred to a university memory clinic increased from $6 \%$ to $16 \%$ between 2005 and 2012 [22]. Interestingly, these subjects exhibited different sociodemographic and phenotypic features (e.g. lower Mini-Mental State Examination scores and higher prevalence of psychiatric diagnoses) compared to native-born patients.

The present study has several limitations worth mentioning. First, the number of dementia cases amongst migrants was estimated without considering the possible differences in terms of dementia prevalence across different races and ethnicities. Some reports have in fact documented that cognitive disorders are more prevalent amongst non-western immigrants in Europe in general and, in particular, in 
specific ethnic groups. For instance, a study conducted in the Netherlands revealed that mild cognitive impairment and dementia were three to four times more prevalent in most non-western immigrant groups (i.e. Turkish, Moroccan Arabic and Berber, Surinamese Hindustani) compared to the native-born Dutch population [23]. Along the same lines, a higher dementia prevalence was observed amongst people of African-Caribbean country of birth living in the UK compared with their native-born counterparts [24]. It should be noticed that both studies adopted culturefair tools for detecting dementia, thus overcoming (or at least limiting) possible barriers associated with language, poor education and illiteracy. The observed excess of dementia in minority groups was hypothetically attributed to the higher prevalence of vascular risk factors and the lower socioeconomic status. Unfortunately, in Eurostat, detailed data on the countries of origin were available only for a minority of migrants. This was not conducive to performing additional analyses accounting for the different prevalence rates of dementia across world countries/regions. Secondly, the lack of updated data for Germany, one of the main destinations of migrations in Europe, significantly underestimates our findings. In fact, nearly 96500 cases of dementia amongst foreign-born subjects have been estimated in this country by considering more recent data (i.e. almost 60000 more cases than our estimates) [25]. Finally, additional determinants (e.g. life expectancy, education, comorbidities, lifestyle, cognitive reserve, socioeconomic status) that may significantly affect the risk of dementia (and thus the precision of the estimates of dementia cases) amongst migrants were not considered. In particular, vascular risk factors, depression, low educational levels and physical inactivity have all been consistently associated with an increased risk of dementia [26].

In conclusion, the present findings indicate that dementia in migrants and ethnic minorities constitutes an emerging but already relevant issue for European healthcare systems. The magnitude of this phenomenon and its complexities reinforce the need for coordinated initiatives at both a national and continental level. The epidemiological data provided should be integrated with those coming from 'real world' services in order to better calibrate these actions. In this context, the 'Dementia in immigrants and ethnic minorities living in Italy' project was recently funded by the Italian Ministry of Health in order to explore the public health relevance of dementia in the immigrant population living in Italy. This project should ideally be coordinated with similar initiatives in order to address this novel issue from an essential continental perspective.

\section{Acknowledgements}

The 'Dementia in immigrants and ethnic minorities living in Italy: clinical-epidemiological aspects and public health perspectives' (ImmiDem) project is supported by a grant of the Italian Ministry of Health (GR-2016-02364975).

\section{Disclosure of conflicts of interest}

The authors have no conflicts of interest to disclose for the present study.

\section{References}

1. International Organization for Migration. Who is a migrant? 2016. https:/www.iom.int/who-is-a-migrant (accessed 17/01/2019)

2. Nielsen TR, Vogel A, Riepe MW, et al. Assessment of dementia in ethnic minority patients in Europe: a European Alzheimer's Disease Consortium survey. Int Psychogeriatr 2011; 23: 86-95.

3. Cooper C, Tandy AR, Balamurali TBS, Livingston G. A systematic review and meta-analysis of ethnic differences in use of dementia treatment, care, and research. Am J Geriatr Psychiatry 2010; 18: 193-203.

4. Kenning C, Daker-White G, Blakemore A, Panagioti M, Waheed W. Barriers and facilitators in accessing dementia care by ethnic minority groups: a meta-synthesis of qualitative studies. BMC Psychiatry 2017; 17: 316.

5. Nielsen TR, Vogel A, Phung TKT, Gade A, Waldemar G. Over- and under-diagnosis of dementia in ethnic minorities: a nationwide register-based study. Int $J$ Geriatr Psychiatry 2011; 26: 1128-1135.

6. Abubakar I, Aldridge RW, Devakumar D, et al. The UCL-Lancet Commission on Migration and Health: the health of a world on the move. Lancet 2018; 392: 26062654.

7. Ardila A, Bertolucci PH, Braga LW, et al. Illiteracy: the neuropsychology of cognition without reading. Arch Clin Neuropsychol 2010; 25: 689-712.

8. Fernández AL, Abe J. Bias in cross-cultural neuropsychological testing: problems and possible solutions. Cult Brain 2018; 6: 1-35.

9. Milani SA, Marsiske M, Cottler LB, Chen X, Striley CW. Optimal cutoffs for the Montreal Cognitive Assessment vary by race and ethnicity. Alzheimers Dement 2018; 10: 773-781.

10. Ranson JM, Langa KM, Llewellyn DJ. Predictors of dementia misclassification when using brief cognitive assessments. Neurol Clin Pract 2019; 9: 1-9.

11. Mukadam N, Cooper C, Livingston G. Improving access to dementia services for people from minority ethnic groups. Curr Opin Psychiatry 2013; 26: 409-414.

12. Stevnsborg L, Jensen-Dahm C, Nielsen TR, Gasse C, Waldemar G. Inequalities in access to treatment and care for patients with dementia and immigrant background: a Danish nationwide study. $J$ Alzheimers Dis 2016; 54: 505-514.

13. Mukadam N, Lewis G, Mueller C, Werbeloff N, Stewart $\mathrm{R}$, Livingston $\mathrm{G}$. Ethnic differences in cognition and age 
in people diagnosed with dementia: a study of electronic health records in two large mental healthcare providers. Int J Geriatr Psychiatry 2019; 34: 504-510.

14. Tillmann J, Schnakenberg R, Puth M-T, Weckbecker K, Just J, Münster E. Barriers in general practitioners' dementia diagnostics among people with a migration background in Germany (BaDeMi) - study protocol for a cross-sectional survey. BMC Med Res Methodol 2018; 18: 124.

15. Canevelli M, Lacorte E, Cova I, et al. Estimating dementia cases in the immigrant population living in Italy. Neurol Sci 2018; 39: 1775-1778.

16. Human Development Index (HDI)|Human Development Reports. http://hdr.undp.org/en/content/human-deve lopment-index-hdi (accessed 26/09/2018)

17. Bacigalupo I, Mayer F, Lacorte E, et al. A systematic review and meta-analysis on the prevalence of dementia in Europe: estimates from the highest-quality studies adopting the DSM IV diagnostic criteria. $J$ Alzheimers Dis 2018; 66: 1471-1481.

18. American Psychiatric Association. Diagnostic and Statistical Manual of Mental Disorders (IV-TR), 4th edntext revised. Washington, DC: American Psychiatric Association, 2000.

19. Alzheimer's Disease International. World Alzheimer Report 2009. http://www.alz.co.uk/research/world-re port-2009 (accessed 07/01/2019)

20. Diaz E, Kumar BN, Engedal K. Immigrant patients with dementia and memory impairment in primary health care in Norway: a national registry study. Dement Geriatr Cogn Disord 2015; 39: 321-331.

21. Lindgren E, Sörenson J, Nägga K, Wattmo C. Equity in dementia care focusing on immigrants in Sweden: a nationwide register-based study. Eur $J$ Public Health 2017; 27(suppl. 3): 51.

22. Segers K, Benoit F, Colson C, Kovac V, Nury D, Vanderaspoilden V. Pioneers in migration, pioneering in dementia: first generation immigrants in a European metropolitan memory clinic. Acta Neurol Belg 2013; 113: $435-440$.

23. Parlevliet JL, Uysal-Bozkir Ö, Goudsmit $\mathrm{M}$, et al. Prevalence of mild cognitive impairment and dementia in older non-western immigrants in the Netherlands: a cross-sectional study. Int J Geriatr Psychiatry 2016; 31: 1040-1049.

24. Adelman S, Blanchard M, Rait G, Leavey G, Livingston G. Prevalence of dementia in African-Caribbean compared with UK-born White older people: two-stage cross-sectional study. $B r \quad J$ Psychiatry 2011; 199: 119125.

25. Monsees J, Hoffmann W, Thyrian JR. Prävalenz von Demenz bei Menschen mit Migrationshintergrund in Deutschland. Z Gerontol Geriatr 2018; 1-7.

26. Norton S, Matthews FE, Barnes DE, Yaffe K, Brayne C. Potential for primary prevention of Alzheimer's disease: an analysis of population-based data. Lancet Neurol 2014; 13: 788-794. 